\title{
Use of Herbal Treatments in Pregnancy
}

Carol LOUIK, Sc.D. ${ }^{1}$, Paula GARDINER, M.D., M.P.H. ${ }^{2}$, Katherine KELLEY, R.Ph. M.P.H. ${ }^{1}$, and Allen A. MITCHELL, M.D. ${ }^{1}$

${ }^{1}$ Slone Epidemiology Center at Boston University, Boston, MA

2 Department of Family Medicine, Boston University, Boston, MA

\begin{abstract}
Objective-Interest in herbal treatments has increased without data on safety, efficacy, or rates of use in pregnancy. We examined antenatal herbal and natural product use among mothers of nonmalformed infants in five geographic centers.

Study Design-We used data on nonmalformed infants from the Slone Epidemiology Center's case-control surveillance program for birth defects to examine rates and predictors of herbal use. Exposures were identified through maternal interview. In addition to overall use, five categories based on traditional uses and two natural product categories were created; topical products and herbalcontaining mulitivitamins were excluded.
\end{abstract}

Results-Among 4,866 mothers of nonmalformed infants, 282 (5.8\%) reported use of herbal or natural treatments. Use varied by study center, and increased with increasing age.

Conclusion-Although rates of use are low, there remains a need for investigation of the safety of these products. Given sparse data on efficacy, even small risks might well outweigh benefits.

\section{Keywords}

complementary medicine; drug safety; herbal treatments; pregnancy

\section{Introduction}

It is widely recognized that use of herbal and complementary medical treatments has increased in the United States over the last decade ${ }^{1}$. While passage of the Dietary Supplements Health and Education Act of 1994 (DSHEA) provided some guidelines for these supplements, the legislation included no safety or efficacy standards that must be met and, unlike medications, FDA does not formally approve dietary supplements prior to marketing.

While use of these products is believed to be increasing, little is known about their use specifically during pregnancy. A few small studies have considered specific subpopulations and geographic regions ${ }^{2-8}$, but there are little data available on current use of herbal treatments among the general population of pregnant women in the U.S. Knowledge of use is particularly important given that there is some evidence to suggest that anxiety about harming the fetus leads some women to avoid pharmaceutical treatment ${ }^{9}$, and it is possible that they may be substituting herbal products, perceived to be more "natural". Alternatively, they may be using

Correspondence: Carol Louik, Sc.D., Slone Epidemiology Center at Boston University, 1010 Commonwealth Ave., Boston, MA 02215. Publisher's Disclaimer: This is a PDF file of an unedited manuscript that has been accepted for publication. As a service to our customers we are providing this early version of the manuscript. The manuscript will undergo copyediting, typesetting, and review of the resulting proof before it is published in its final citable form. Please note that during the production process errors may be discovered which could affect the content, and all legal disclaimers that apply to the journal pertain. 
herbal and other natural products in addition to traditional medications, which raises concerns about possible interactions ${ }^{10}$. Thus it is important to understand the extent to which herbal and other natural treatments are used in pregnancy, the specific products used, the reasons for which they are used, and factors which may predict which women are most likely to use herbal and other natural products. In this report, we examine use in pregnancy of herbal and other natural treatments.

\section{Materials and Methods}

The Slone Epidemiology Center at Boston University has been conducting the Birth Defects Study (also known as the Pregnancy Health Interview Study), a form of case-control surveillance to identify the risks and safety of various antenatal environmental exposures, particularly medications, in relation to birth defects since 1976; the methods have been described previously 11,12 . Since the study's inception, infants with birth defects have been identified in birth and tertiary care hospitals in various geographic areas and since 1993, a sample of non-malformed infants was also identified at study hospitals in all study centers. Depending on the size of the hospital, between three and ten non-malformed infants are selected at random from hospital discharge lists. In 1998, ascertainment of malformed subjects was modified in Massachusetts to involve the state's birth defects registry system, and an analogous change was made to identify non-malformed infants from a random sample of birth certificates. The current report is based on mothers of non-malformed infants included in the study from five study centers (greater Philadelphia, greater Toronto, San Diego, and state-based birth defects registries in Massachusetts and New York State) who were interviewed between 1998 and 2006 .

Mothers of eligible subjects are interviewed within six months of the baby's birth by trained nurse-interviewers using a standardized questionnaire. The interview elicits demographic information about the mother and father and detailed information regarding maternal illnesses and medications used from 2 months prior to the last menstrual period (LMP) through the end of pregnancy. This study has been approved by Boston University Medical Center's Institutional Review Board (IRB) and, as appropriate, the IRBs of participating institutions, and informed consent is obtained from all participants.

Information on drug exposures during the time period from 2 months prior to the date of the last menstrual period (LMP) through the end of pregnancy is elicited through a series of questions designed to maximize recall and accuracy of reporting. We inquire first about illnesses that subjects may have had, and any treatments used for them. The women are then asked about common indications for medication use (e.g. headache, depression, heartburn, fluid retention), specific medication categories (e.g., vitamins, antibiotics, laxatives), and finally specific medications (e.g. Advil, Tylenol products, Prozac, Allegra). Each of these questions includes the following statement "Please include medications prescribed by a health care provider and medications you may have obtained without a prescription from stores, pharmacies, friends, or relatives, as well as herbal or home remedies." Women who report use of any treatment are asked to retrieve the bottle or package if it is still available.

For this analysis, we considered a product to be "herbal" if it contained one or more ingredients that were botanical in origin, regardless of the part of the plant from which the ingredient is derived. We excluded topical treatments and all multivitamins whether or not they contained an herbal ingredient from the analysis. Because this is a survey of reported use of herbal and other natural products rather than an investigation of risks and safety of specific ingredients, we focused primarily on products rather than specific ingredients, although we also examined four ingredients thought to be of particular interest—chamomile, ephedra, ginger, and ginseng. 
We created five categories of products based on their traditional uses: cough and cold remedies (e.g., echinacea, arnica), nausea and vomiting of pregnancy (NVP) (e.g., ginger, raspberry), psychiatric and sleep disorders (e.g., valerian, Gingko biloba), weight loss or sports enhancement (e.g., Metabolife ${ }^{\circledR}$, ginseng), and bladder or other "female" problems (e.g., chamomile, cranberry juice). We also investigated two additional natural product categories: probiotics (e.g., acidophilus), and lipids and omega fatty acids (e.g., fish oil, evening primrose oil). A given product could be included in more than one of these categories, if appropriate (e.g., ginseng is included in both "cough and cold remedies" and "weight loss or sports enhancement"). A woman was considered to be exposed if she reported use of the product at any time from two months prior to the LMP through the end of pregnancy; use according to month of gestation was also investigated.

We examined a wide range of potential predictors of use of herbal and other natural treatments in pregnancy: age, ethnicity, education, family income, marital status, body mass index (BMI), smoking status, alcohol consumption, coffee and tea consumption, parity, history of chronic conditions including asthma, diabetes, hypertension, and herpes, conditions occurring during pregnancy including respiratory infections, morning sickness, urinary tract infections, fevers, and toxemia, use of prescription or non-prescription medications (other than herbal), study center, and LMP year. Multiple logistic regression was used to evaluate each potential risk factor while controlling for the effects of others.

\section{Results}

There were 4,866 interviews of mothers of nonmalformed infants available for study, with LMP years between 1997 and 2005. Among women we were able to locate, the participation rate was 68.0\%; this rate ranged from 64\% in New York to 61\% in Massachusetts.

Massachusetts subjects represented about $60 \%$ of the study sample, Philadelphia about $15 \%$, Toronto 13\%, and the remainder from San Diego and New York State. Overall, 282 women $(5.8 \%)$ reported using an herbal and other natural treatment. As shown in Figure 1, use varied considerably by center.

Table 1 reveals a clear increase in use with increasing age ( $\mathrm{p}<.05)$, but few other factors seemed related to overall herbal and other natural product use. Hispanic women reported more herbal and other natural use compared to whites, but the $95 \%$ confidence interval included 1.0. There was no evidence that use of herbal and other natural products increased over time. Women who experienced nausea and vomiting during pregnancy or who had a respiratory infection had higher rates of herbal and other natural use than women who did not (see below), and it is interesting to note that women who drank decaffeinated coffee or tea were also slightly more likely to use herbal or other natural products.

The rates of use of for each of the categories of herbal and other natural preparations based on their traditional uses are presented in Table 2. We evaluated the same factors as possible predictors of use of these categories. Because rates of use were low, most confidence intervals were wide and included 1.0 (data not shown), but there were some factors that suggested differences, and these differed across the categories. Selected results are shown in Table 3. As was true for overall use, use of most herbal and other natural classes varied by center, but psychiatric and sleep disorders and weight loss or sports enhancement treatments showed little variation. Several classes of herbs were related to tea consumption (NVP, probiotics, and lipids and omega fatty acids), while others were more related to coffee consumption (psychiatric and sleep disorders and weight loss or sports enhancement). There were several categories which were inversely related to alcohol use prior to pregnancy, including cough and cold remedies, psychiatric and sleep disorders, and probiotics. 
It is useful to note that all women who used a cough or cold herbal remedy reported having an upper respiratory infection. Similarly, women who experienced nausea and vomiting were much more likely to have used an NVP herbal $(\mathrm{OR}=10.9,95 \% \mathrm{CI}=2.6-46)$, and women who reported urinary tract infections were more likely to have used an herbal treatment for bladder or "female" problems $(\mathrm{OR}=3.5,95 \% \mathrm{CI}=1.8-6.8)$. Obese women were more likely to have used a weight loss or sports enhancement herbal $(\mathrm{OR}=1.8,95 \% \mathrm{CI}=0.8-4.0)$.

The most commonly reported herbal preparations (excluding vitamins) were ginger (0.6\%), echinacea $(0.6 \%)$, fish oil $(0.4 \%)$, herbal tea $(0.4 \%)$, cranberry $(0.2 \%)$ and Metabolife ${ }^{\circledR}$ (Vitamin E, magnesium, zinc, chromium, and a proprietary blend of herbs including ephedra) $(0.2 \%)$. (Metabolife was removed from the market early in 2004 and no use was reported after that time; we have adjusted the denominator to correspond to the appropriate time period.) $\mathrm{We}$ examined these according to gestational month of use (Figure 2). Although the number of women reporting use in each month is too small to draw inferences, it is important to note that use of Metabolife ${ }^{\circledR}$, a weight loss product, was limited to the two months prior to the LMP and the first gestational month, and that use of ginger, a product used for nausea and vomiting, peaked during the first trimester.

\section{Comment}

Use of herbal and other natural treatments has been reported to be increasing in the United States and Canada, and as acceptance of alternative medicine therapies as valid treatments grows, herbal and other natural use is likely to continue. Because herbal and other natural remedies are not regulated to the same degree as traditional pharmaceutical products, it is important to monitor their use, and this is particularly the case in pregnancy, a potentially vulnerable time for both mother and fetus. In this study, we found that although herbal and other natural products as a group are used by approximately $6 \%$ of pregnant women, use of individual products is quite low, with the most common (ginger and echinacea) reported by only $0.6 \%$ of pregnant women. Rates of use of herbal and other natural treatments have remained fairly consistent over time.

Increasing age was associated with greater use of herbal and other natural products as a whole, as has been reported by other investigators ${ }^{3}, 13,14$, but the factor most strongly and consistently associated with herbal and other natural use was geographic region. This association remained strong even after adjustment for race and ethnicity and may reflect cultural variations across regions that encompass factors beyond race and ethnicity. This observation would support previous studies of herbal use in pregnancy conducted in specific populations that found varying rates of herbal use. Among these populations, use ranged from 59\% among rural West Virginia women ${ }^{3}$ to $24 \%$ among women in Taiwan ${ }^{15}$. Although these differences may be largely explained by varying definitions of herbal products, it is interesting that among the Australian women, large difference were noted depending on the mother's country of birth ${ }^{3}$. In the present study, it is also important to note that about $60 \%$ of subjects came from a single center, Massachusetts.

When we examined use of herbal and other natural treatments according to their traditional uses, we found indirect evidence to suggest that these products are largely used for their intended purpose. All women who used a cough/cold treatment reported having had an upper respiratory infection, most women who used a product for NVP had experienced episodes of NVP during their pregnancies, and most women who used products for bladder conditions had had a urinary tract infection. We also found that the gestational timing of use of some of these products was consistent with their traditional uses: ginger, an acknowledged treatment for nausea and vomiting, was most commonly used during the first trimester, when NVP is most likely to occur. 
Our overall rate of use is somewhat lower than has been reported by others ${ }^{16}$, for which there are several possible explanations. Definitions of herbal products differ among studies, with some considering all forms of nutritional supplements and others using more restricted definitions. In the present study, we excluded all topical treatments and all multivitamins containing herbs, and included only those teas that were reported in response to a question concerning medication use. Including multivitamins would have yielded higher rates of herbal use, but could have been misleading because women may have been unaware that the multivitamin they used contained a single herb, e.g. lycopene. (In fact, we found that of the 85 distinct multivitamin products reported by women in this study, $55(65 \%)$ contained at least one herbal ingredient). Our rate of use is similar to the one other study that also excluded multivitamins ${ }^{13}$; Refuerzo et al, using subjects from a single, urban hospital found that, after excluding prenatal vitamins and iron supplements, $4.1 \%$ of women reported using an herbal or other natural remedy, which is slightly lower than our overall rate of $5.8 \%$.

In a study such as this, where medication use is collected retrospectively, one must be concerned about the accuracy of reported exposures. While all interviews were conducted within 6 months of delivery, the time interval between exposure and interview could be, in some instances, close to 18 months, and it is quite possible that some women were unable to recall substances that were used infrequently. While our interview is designed to maximize recall by using a series of prompts to elicit drug use and a calendar to help focus on dates, reporting may still be incomplete. However, it is unlikely that underreporting would affect the relative frequency of use of specific herbal and other natural products.

These data derive from an ongoing program of case-control surveillance for risk factors for congenital malformations and represent one of the largest studies to date of herbal treatments in pregnancy. In this report, we examined use of products as they are purchased and not individual components of these products. The fact that overall use was relatively low (5.8\%), and use of specific individual products was even lower does not diminish the need for further investigation of their safety during pregnancy. Indeed, several studies have identified concerns that should be further explored ${ }^{17-} 21$, particularly in view of the fact that evidence of the efficacy of these products is largely unstudied. In the absence of evidence that most of the studied herbal and other natural products confer benefit to the pregnant woman, it is particularly important to identify even small risks, which would appreciably affect the benefit-risk calculus. Further studies should focus on the safety of specific herbal and other natural ingredients found in these products with respect to wide range of pregnancy conditions and outcomes.

\section{Acknowledgments}

We thank Dawn Jacobs, RN, MPH, Fiona Rice, MPH, Rita Krolak, RN, Kathleen Sheehan, RN, Moira Quinn, RN, Clare Coughlin, RN, Nancy Rodriquez-Sheridan, Carolina Meyers and Meghan Malone-Moses, MPH for their assistance in data collection and Nastia Dynkin for computer programming; the staff of the Massachusetts Department of Public Health Center for Birth Defects Research and Prevention, Dr. Charlotte Druschel and the New York State Health Department, and Drs. Christina Chambers and Kenneth Jones of the University of California, San Diego, as well as the medical and nursing staff at all participating hospitals for assistance with case ascertainment: Baystate Medical Center, Beth Israel Deaconess Medical Center, Boston Medical Center, Brigham \& Women's Hospital, Brockton Hospital, Cambridge Hospital, Caritas Good Samaritan Medical Center, Charlton Memorial Hospital, Children's Hospital, Emerson Hospital, Falmouth Hospital, Haverhill-Hale Hospital, Jordan Hospital, Kent Hospital, Lawrence General Hospital, Lowell General Hospital, Melrose-Wakefield Hospital, Metro West Medical CenterFramingham, Mt. Auburn Hospital, New England Medical Center, Newton-Wellesley Hospital, North Shore Medical Center, Rhode Island Hospital, Saints Memorial Medical Center, South Shore Hospital, Southern New Hampshire Medical Center, St. Elizabeth's Medical Center, St. Luke's Hospital, St. Vincent Hospital, UMASS Memorial Health Care, Women \& Infants' Hospital, Abington Memorial Hospital, Albert Einstein Medical Center, Alfred I. duPont Hospital for Children, Bryn Mawr Hospital, Chester County Hospital, Children's Hospital of Philadelphia, Christiana Care Health Services, Community Hospital, Crozer-Chester Medical Center, Doylestown Hospital, Frankford Hospital, Hahnemann University Hospital, The Hospital of the University of Pennsylvania, Lankenau Hospital, Lancaster General Hospital, Lehigh Valley Hospital, Nanticoke Memorial Hospital, Pennsylvania Hospital, Sacred Heart Hospital, St. Christopher's Hospital for Children, St. Mary Medical Center, Temple University Health Sciences 
Center, Reading Hospital \& Medical Center, Thomas Jefferson University Hospital, Grand River Hospital, Guelph General Hospital, Hamilton Health Sciences Corporation, The Hospital for Sick Children, Humber River Regional Hospital-Church Site, Humber River Regional Hospital-Finch Site, Joseph Brant Memorial Hospital, Lakeridge Health Corporation, London Health Sciences Center, Mt. Sinai Hospital, North York General Hospital, Oakville Trafalgar Memorial Hospital, Scarborough Hospital-General Division, Scarborough Hospital-Grace Division, St. Joseph's Health Centre-London, St. Joseph's Health Centre-Toronto, St. Joseph's Healthcare-Hamilton, St. Michael's Hospital, Sunnybrook \& Women's College Health Sciences Center, Toronto East General Hospital, Toronto General Hospital, Trillium Health Center, William Osler Heath Centre, York Central Hospital, York County Hospital, Alvarado Hospital, Balboa Naval Medical Center, Camp Pendleton Naval Hospital, Children's Hospital and Health Center, Kaiser Zion Medical Center, Palomar Medical Center, Pomerado Hospital, Scripps Mercy Hospital, Scripps Memorial HospitalChula Vista, Scripps Memorial Hospital-Encinitas, Scripps Memorial Hospital-La Jolla, Sharp Chula Vista Hospital, Sharp Coronado Hospital, Sharp Grossmont Hospital, Sharp Mary Birch Hospital, Tri-City Medical Center, and UCSD Medical Center.; we particularly thank all the mothers who participated in the study.

This work was supported in part by the National Institutes of Child Health and Human Development grant HD27697, the National Heart, Lung, and Blood Institutes grant HL 50763, and Cooperative Agreement number U50/CCU113247 with the Centers for Disease Control through the Massachusetts Department of Public Health. Additional support for the Slone Epidemiology Center Birth Defects Study was provided by Aventis, Inc., and Sanofi Pasteur, Inc.

\section{References}

1. Barnes PM, Powell-Griner E, McFann K, Nahin RL. Complementary and alternative medicine use among adults: United States, 2002. Adv Data 2004;343:1-19. [PubMed: 15188733]

2. Allaire AD, Moos MK, Wells SR. Complementary and alternative medicine in pregnancy: a survey of North Carolina certified nurse-midwives. Obstet Gynecol 2000;95(1):19-23. [PubMed: 10636495]

3. Forster DA, Denning A, Wills G, Bolger M, McCarthy E. Herbal medicine use during pregnancy in a group of Australian women. BMC Pregnancy Childbirth 2006;6:21. [PubMed: 16780602]

4. Glover DD, Rybeck BF, Tracy TS. Medication use in a rural gynecologic population: prescription, over-the-counter, and herbal medicines. Am J Obstet Gynecol 2004;190(2):351-7. [PubMed: 14981373]

5. Nordeng H, Havnen GC. Use of herbal drugs in pregnancy: a survey among 400 Norwegian women. Pharmacoepidemiol Drug Saf 2004;13(6):371-80. [PubMed: 15170766]

6. Hepner DL, Harnett M, Segal S, Camann W, Bader AM, Tsen LC. Herbal medicine use in parturients. Anesth Analg 2002;94(3):690-3. [PubMed: 11867399]

7. Tsui B, Dennehy CE, Tsourounis C. A survey of dietary supplement use during pregnancy at an academic medical center. Am J Obstet Gynecol 2001;185(2):433-7. [PubMed: 11518905]

8. Gibson PPR, Star J. Herbal and alternative medicine use during pregnancy: A cross-sectional survey. Obstet Gynecol 2001;97(4 Suppl 1):S44-S5.

9. Enriquez R, Wu P, Griffin MR, et al. Cessation of asthma medication in early pregnancy. Am J Obstet Gynecol 2006;195(1):149-53. [PubMed: 16631099]

10. Sood A, Sood R, Brinker FJ, Mann R, Loehrer LL, Wahner-Roedler DL. Potential for interactions between dietary supplements and prescription medications. Am J Med 2008;121(3):207-11. [PubMed: 18328304]

11. Mitchell AA, Rosenberg L, Shapiro S, Slone D. Birth defects related to Bendectin use in pregnancy. I. Oral clefts and cardiac defects. JAMA 1981;245(22):2311-4. [PubMed: 7230459]

12. Werler MM, Hayes C, Louik C, Shapiro S, Mitchell AA. Multivitamin supplementation and risk of birth defects. Am J Epidemiol 1999;150(7):675-82. [PubMed: 10512421]

13. Refuerzo JS, Blackwell SC, Sokol RJ, et al. Use of over-the-counter medications and herbal remedies in pregnancy. Am J Perinatol 2005;22(6):321-4. [PubMed: 16118721]

14. Holst L, Nordeng H, Haavik S. Use of herbal drugs during early pregnancy in relation to maternal characteristics and pregnancy outcome. Pharmacoepidemiol Drug Saf 2008;17(2):151-9. [PubMed: 17992658]

15. Chuang CH, Hsieh WS, Guo YL, et al. Chinese herbal medicines used in pregnancy: a populationbased survey in Taiwan. Pharmacoepidemiol Drug Saf 2007;16(4):464-8. [PubMed: 17063532]

16. Ernst E. Herbal medicinal products during pregnancy: are they safe? Bjog 2002;109(3):227-35. [PubMed: 11950176] 
17. Dugoua JJ, Mills E, Perri D, Koren G. Safety and efficacy of ginkgo (Ginkgo biloba) during pregnancy and lactation. Can J Clin Pharmacol 2006;13(3):e277-84. [PubMed: 17085776]

18. Dugoua JJ, Mills E, Perri D, Koren G. Safety and efficacy of St. John's wort (hypericum) during pregnancy and lactation. Can J Clin Pharmacol 2006;13(3):e268-76. [PubMed: 17085775]

19. Dugoua JJ, Seely D, Perri D, Koren G, Mills E. Safety and efficacy of black cohosh (Cimicifuga racemosa) during pregnancy and lactation. Can J Clin Pharmacol 2006;13(3):e257-61. [PubMed: 17085773]

20. Marcus DM, Snodgrass WR. Do no harm: avoidance of herbal medicines during pregnancy. Obstet Gynecol 2005;105(5 Pt 1):1119-22. [PubMed: 15863553]

21. Pinto RM, Fernandes ES, Reis JE, Peters VM, de Guerra MO. Intra-uterine growth retardation after prenatal administration of Ginkgo biloba to rats. Reprod Toxicol 2007;23(4):480-5. [PubMed: 17287108] 


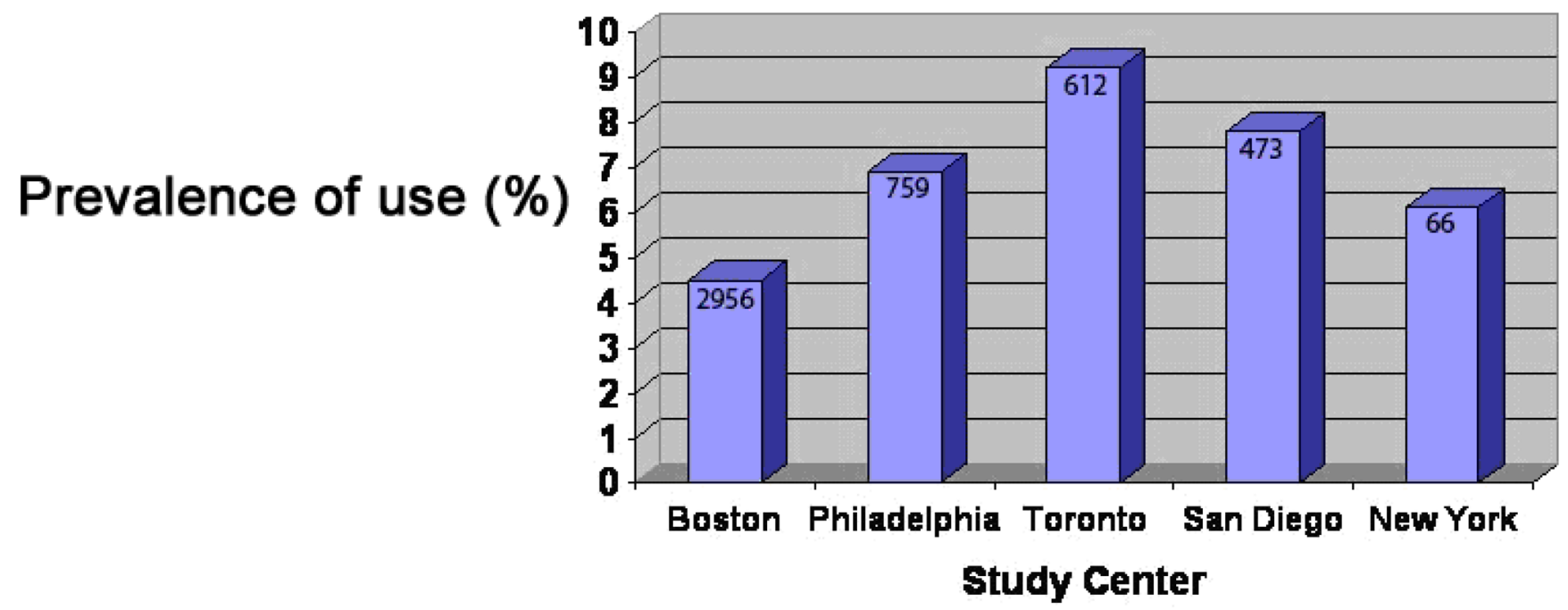

Figure 1.

Overall Herbal and Natural Product Use According to Study Center Among 4,866 Mothers of Nonmalformed Infants 


\section{Prevalence of use (\%)}

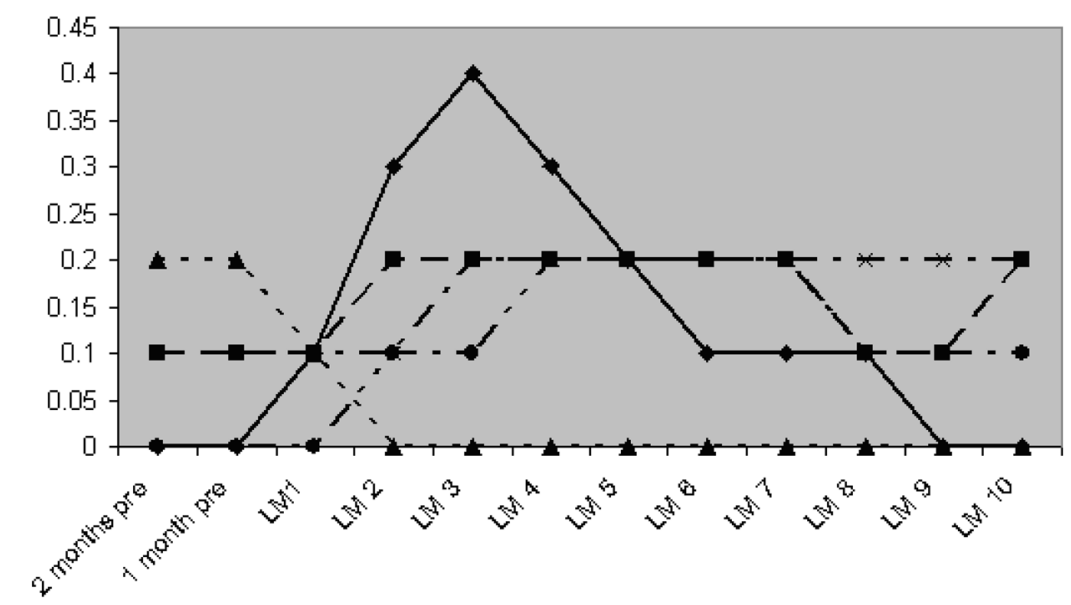

\section{Lunar Month of Pregnancy}

$\longrightarrow$-Ginger - - Echinacea - -4- - Metabolife $-\times-$ Fish Oil - - - Herbal Tea

Figure 2.

Most Commonly Reported Herbal and Natural Products According to Gestational Month of Use Among 4,866 Mothers of Nonmalformed Infants

$\mathrm{GM}=$ Gestational month 
Table 1

Factors associated with use of herbal and other natural product treatments during pregnancy among 4,866 Mothers of Nonmalformed Infants.

\begin{tabular}{|c|c|c|c|c|}
\hline \multirow[b]{2}{*}{ Women's Characteristics } & \multicolumn{2}{|c|}{ Any Herbal Use ( $N=282$} & \multirow[b]{2}{*}{ Crude OR [95\% CI] } & \multirow[b]{2}{*}{ Adjusted OR* $[95 \% \mathrm{CI}]$} \\
\hline & $\mathbf{n}$ & $\%$ & & \\
\hline \multicolumn{5}{|l|}{ Age (years) } \\
\hline$<20$ & 8 & 2.2 & $0.39[0.19,0.82]$ & $0.52[0.19,1.42]$ \\
\hline $20-24$ & 34 & 5.2 & $0.95[0.62,1.46]$ & $0.74[0.44,1.26]$ \\
\hline $25-29$ (ref.) & 66 & 5.4 & 1.00 Reference & 1.00 Reference \\
\hline $30-34$ & 106 & 6.2 & $1.15[0.84,1.58]$ & $1.19[0.84,1.68]$ \\
\hline $35-39$ & 53 & 6.7 & $1.24[0.86,1.81]$ & $1.34[0.88,2.04]$ \\
\hline$>=40$ & 14 & 13.5 & $2.71[1.47,5.02]$ & $2.95[1.49,5.83]$ \\
\hline \multicolumn{5}{|l|}{ BMI } \\
\hline Underweight & 5 & 2.2 & $0.35[0.14,0.86]$ & $0.30[0.11,0.81]$ \\
\hline Normal (ref.) & 184 & 6 & 1.00 Reference & 1.00 Reference \\
\hline Overweight & 64 & 6.6 & $1.10[0.82,1.48]$ & $0.91[0.66,1.27]$ \\
\hline Obese & 24 & 4.4 & $0.72[0.47,1.12]$ & $0.70[0.43,1.14]$ \\
\hline \multicolumn{5}{|l|}{ Ethnic Background } \\
\hline White (ref.) & 205 & 5.8 & 1.00 Reference & 1.00 Reference \\
\hline African origin & 15 & 4.4 & $0.74[0.44,1.27]$ & $1.16[0.62,2.17]$ \\
\hline Other & 24 & 6.8 & $1.19[0.77,1.84]$ & $1.44[0.87,2.39]$ \\
\hline Hispanic & 38 & 6.1 & $1.05[0.73,1.50]$ & $1.58[0.98,2.54]$ \\
\hline \multicolumn{5}{|l|}{ Smokers } \\
\hline During Pregnancy & 29 & 5.6 & $1.12[0.74,1.69]$ & $1.40[0.85,2.29]$ \\
\hline Never (ref.) & 142 & 5 & 1.00 Reference & 1.00 Reference \\
\hline Before Pregnancy & 111 & 7.3 & $1.48[1.15,1.91]$ & $1.31[0.97,1.76]$ \\
\hline \multicolumn{5}{|l|}{ Education (years) } \\
\hline$<$ H.S. & 12 & 2.7 & $0.42[0.23,0.77]$ & $0.41[0.17,1.00]$ \\
\hline Completed H.S. (ref.) & 132 & 6.2 & 1.00 Reference & 1.00 Reference \\
\hline More than H.S. & 138 & 6 & $0.96[0.75,1.22]$ & $0.85[0.63,1.17]$ \\
\hline \multicolumn{5}{|l|}{ Income (\$/yr) } \\
\hline$<10,000$ & 8 & 3.4 & $0.54[0.26,1.12]$ & $0.80[0.32,2.05]$ \\
\hline $10,000-45,000$ & 65 & 5.7 & $0.92[0.69,1.23]$ & $1.03[0.71,1.48]$ \\
\hline$>45,000$ (ref.) & 190 & 6.2 & 1.00 Reference & 1.00 Reference \\
\hline \multicolumn{5}{|l|}{ Center } \\
\hline Boston (ref.) & 133 & 4.5 & 1.00 Reference & 1.00 Reference \\
\hline Philadelphia & 52 & 6.9 & $1.56[1.12,2.17]$ & $1.40[0.95,2.07]$ \\
\hline Toronto & 56 & 9.2 & $2.14[1.54,2.96]$ & $2.13[1.49,3.06]$ \\
\hline San Diego & 37 & 7.8 & $1.80[1.23,2.63]$ & $2.23[1.41,3.52]$ \\
\hline New York & 4 & 6.1 & $1.37[0.49,3.82]$ & $1.11[0.32,3.89]$ \\
\hline \multicolumn{5}{|l|}{ LMP Year } \\
\hline 1997-1998 & 49 & 5.3 & $0.83[0.55,1.26]$ & $1.01[0.62,1.65]$ \\
\hline 1999-2000 & 96 & 6.6 & $1.05[0.73,1.50]$ & $1.20[0.77,1.87]$ \\
\hline
\end{tabular}




\begin{tabular}{|c|c|c|c|c|}
\hline \multirow[b]{2}{*}{ Women's Characteristics } & \multicolumn{2}{|c|}{ Any Herbal Use $(\mathrm{N}=282)$} & \multirow[b]{2}{*}{ Crude OR [95\% CI] } & \multirow[b]{2}{*}{ Adjusted OR* $[95 \% \mathrm{CI}]$} \\
\hline & $\mathbf{n}$ & $\%$ & & \\
\hline 2001-2002 & 91 & 5.2 & $0.81[0.56,1.16]$ & $0.75[0.49,1.14]$ \\
\hline 2003-2005 (ref.) & 46 & 6.3 & 1.00 Reference & 1.00 Reference \\
\hline \multicolumn{5}{|l|}{ Alcohol Use } \\
\hline During Pregnancy & 108 & 7.2 & $1.33[1.02,1.74]$ & $1.34[0.82,1.57]$ \\
\hline Never (ref.) & 124 & 5.5 & 1.00 Reference & 1.00 Reference \\
\hline Before Pregnancy & 49 & 4.5 & $0.81[0.58,1.13]$ & $0.68[0.46,1.01]$ \\
\hline \multicolumn{5}{|l|}{ Marital Status } \\
\hline Married (ref.) & 215 & 6 & 1.00 Reference & 1.00 Reference \\
\hline Other & 67 & 5.3 & $0.89[0.67,1.18]$ & $1.25[0.84,1.85]$ \\
\hline \multicolumn{5}{|l|}{ Total Pregnancies } \\
\hline 1 (ref.) & 72 & 4.8 & 1.00 Reference & 1.00 Reference \\
\hline 2 & 93 & 6.1 & $1.28[0.94,1.76]$ & $1.14[0.80,1.64]$ \\
\hline $3+$ & 117 & 6.4 & $1.35[1.00,1.82]$ & $1.12[0.78,1.60]$ \\
\hline \multicolumn{5}{|l|}{ Coffee Use } \\
\hline Never (ref.) & 80 & 4.4 & 1.00 Reference & 1.00 Reference \\
\hline Ever & 197 & 6.6 & $0.65[0.50,0.85]$ & $1.11[0.80,1.53]$ \\
\hline \multicolumn{5}{|l|}{ Decaf. Coffee Use } \\
\hline Never (ref.) & 161 & 4.9 & 1.00 Reference & 1.00 Reference \\
\hline Ever & 117 & 7.7 & $0.62[0.49,0.80]$ & $1.37[1.02,1.84]$ \\
\hline \multicolumn{5}{|l|}{ Tea Use } \\
\hline Never & 78 & 3.9 & 1.00 Reference & 1.00 Reference \\
\hline Ever & 201 & 7.2 & $1.91[1.46,2.50]$ & $1.77[1.30,2.39]$ \\
\hline \multicolumn{5}{|l|}{ Asthma } \\
\hline No & 271 & 5.9 & 1.00 Reference & 1.00 Reference \\
\hline Yes & 11 & 4.5 & $1.31[0.71,2.42]$ & $1.39[0.44,4.39]$ \\
\hline \multicolumn{5}{|l|}{ Diabetes } \\
\hline No & 272 & 5.9 & 1.00 Reference & 1.00 Reference \\
\hline Yes & 10 & 4.3 & $1.40[0.73,2.66]$ & $1.37[0.49,3.85]$ \\
\hline \multicolumn{5}{|l|}{ Hypertension } \\
\hline No & 258 & 5.9 & 1.00 Reference & 1.00 Reference \\
\hline Yes & 24 & 5.1 & $1.15[0.75,1.77]$ & $177[0.61,5.18]$ \\
\hline \multicolumn{5}{|l|}{ Herpes } \\
\hline No & 278 & 5.8 & 1.00 Reference & 1.00 Reference \\
\hline Yes & 4 & 4.5 & $1.30[0.47,3.56]$ & $1.34[0.32,5.55]$ \\
\hline \multicolumn{5}{|l|}{ Chronic Condition } \\
\hline No & 237 & 6.1 & 1.00 Reference & 1.00 Reference \\
\hline Yes & 45 & 4.7 & $0.76[0.55,1.05]$ & $0.51[0.17,1.55]$ \\
\hline \multicolumn{5}{|l|}{ Upper Respiratory Infection } \\
\hline No & 87 & 4.4 & 1.00 Reference & 1.00 Reference \\
\hline Yes & 195 & 6.7 & $1.55[1.20,2.01]$ & $1.41[1.04,1.89$ \\
\hline
\end{tabular}




\begin{tabular}{|c|c|c|c|c|}
\hline \multirow[b]{2}{*}{ Women's Characteristics } & \multicolumn{2}{|c|}{ Any Herbal Use (N=282) } & \multirow[b]{2}{*}{ Crude OR [95\% CI] } & \multirow[b]{2}{*}{ Adjusted OR* $[95 \% \mathrm{CI}]$} \\
\hline & $\mathbf{n}$ & $\%$ & & \\
\hline No & 207 & 5.5 & 1.00 Reference & 1.00 Reference \\
\hline Yes & 75 & 7 & $0.77[0.58,1.01]$ & $1.03[0.76,1.41]$ \\
\hline \multicolumn{5}{|l|}{ Urinary Tract Infection } \\
\hline No & 241 & 5.6 & 1.00 Reference & 1.00 Reference \\
\hline Yes & 41 & 7.2 & $1.30[0.92,1.83]$ & $1.42[0.96,2.10]$ \\
\hline \multicolumn{5}{|l|}{ Toxemia } \\
\hline No & 275 & 5.8 & 1.00 Reference & 1.00 Reference \\
\hline Yes & 7 & 5.1 & $0.88[0.41,1.90]$ & $0.79[0.31,2.01]$ \\
\hline \multicolumn{5}{|l|}{ Morning Sickness } \\
\hline No & 91 & 4.8 & 1.00 Reference & 1.00 Reference \\
\hline Yes & 191 & 6.5 & $1.38[1.07,1.78]$ & $1.43[1.07,1.89]$ \\
\hline
\end{tabular}




\section{Table 2}

Rates of use of herbal and natural product classes defined by intended use among 4,866 Mothers of Nonmalformed Infants.

\begin{tabular}{lcc}
\hline Intended Use & No. & $\%$ \\
\hline Probiotics & 92 & $1.90 \%$ \\
Bladder or "female" problems & 56 & $1.20 \%$ \\
Cough and cold remedies & 56 & $1.20 \%$ \\
Weight loss or sports enhancement & 52 & $1.10 \%$ \\
Nausea and vomiting of pregnancy & 46 & $1.10 \%$ \\
Lipids and omega fatty acids & 43 & $0.90 \%$ \\
Psychiatric and sleep disorders & 26 & $0.50 \%$ \\
\hline
\end{tabular}


Table 3

Selected Factors Associated with Categories of Herbal and Other Natural Product Use Among 4,866 Mothers of Nonmalformed Infants

\begin{tabular}{|c|c|c|c|}
\hline & No. Exposed & Crude OR (95 \% CI) & Adj OR (95\% CI) \\
\hline Cough and cold remedies & 56 & & \\
\hline \multicolumn{4}{|l|}{ Center } \\
\hline Boston (ref.) & 22 & 1.00 Reference & 1.00 Reference \\
\hline Philadelphia & 14 & $2.54[1.29,4.99]$ & $2.92[1.32,6.47]$ \\
\hline Toronto & 13 & $3.00[1.50,5.99]$ & $3.28[1.51,7.13]$ \\
\hline San Diego & 7 & $2.06[0.88,4.85]$ & $3.13[1.03,9.48]$ \\
\hline New York & 0 & $0.00[0.00,]$. & $0.00[0.00,]$. \\
\hline \multicolumn{4}{|l|}{ Alcohol Use } \\
\hline During Pregnancy & 21 & $1.11[0.63,1.95]$ & $1.00[0.50,2.02]$ \\
\hline Never (ref.) & 29 & 1.00 Reference & 1.00 Reference \\
\hline Before Pregnancy & 5 & $0.35[0.14,0.91]$ & $0.31[0.11,0.87]$ \\
\hline \multicolumn{4}{|l|}{ Upper respiratory infection } \\
\hline No & 0 & 1.00 Reference & 1.00 Reference \\
\hline Yes & 56 & & \\
\hline Nausea and vomiting & 46 & & \\
\hline \multicolumn{4}{|l|}{ Center } \\
\hline Boston (ref.) & 16 & 1.00 Reference & 1.00 Reference \\
\hline Philadelphia & 13 & $3.24[1.55,6.78]$ & $2.66[1.04,6.84]$ \\
\hline Toronto & 9 & $2.86[1.26,6.50]$ & $3.32[1.28,8.60]$ \\
\hline San Diego & 7 & $2.83[1.16,6.93]$ & $3.80[1.35,10.68]$ \\
\hline New York & 1 & $2.85[0.37,21.80]$ & $2.95[0.30,28.81]$ \\
\hline \multicolumn{4}{|l|}{ Tea Use } \\
\hline Never & 12 & 1.00 Reference & 1.00 Reference \\
\hline Ever & 33 & $2.04[1.05,3.96]$ & $2.26[0.95,5.42]$ \\
\hline \multicolumn{4}{|l|}{ Morning Sickness } \\
\hline No & 4 & 1.00 Reference & 1.00 Reference \\
\hline Yes & 42 & $6.90[2.47,19.26]$ & $10.90[2.58,45.98]$ \\
\hline Psychiatric and sleep disorders & 26 & & \\
\hline \multicolumn{4}{|l|}{ Center } \\
\hline Boston (ref.) & 18 & 1.00 Reference & 1.00 Reference \\
\hline Philadelphia & 1 & $0.22[0.30,1.66]$ & $0.28[0.04,2.19]$ \\
\hline Toronto & 5 & $1.41[0.52,3.82]$ & $0.71[0.20,2.61]$ \\
\hline San Diego & 2 & $0.72[0.17,3.11]$ & $1.11[0.21,5.91]$ \\
\hline New York & 0 & $0.00[0.00,]$. & $0.00[0.00,]$. \\
\hline \multicolumn{4}{|l|}{ Alcohol Use } \\
\hline During Pregnancy & 15 & $4.60[1.67,12.67]$ & $4.59[1.20,17.53]$ \\
\hline Never (ref.) & 5 & 1.00 Reference & 1.00 Reference \\
\hline Before Pregnancy & 6 & $2.4(0.7,8.0)$ & $2.32[0.50,10.66]$ \\
\hline
\end{tabular}




\begin{tabular}{|c|c|c|c|}
\hline & No. Exposed & Crude OR (95 \% CI) & Adj OR (95\% CI) \\
\hline Never (ref.) & 3 & 1.00 Reference & 1.00 Reference \\
\hline Ever & 20 & $4.17[1.24,14.04]$ & $2.46[0.68,8.94]$ \\
\hline Weight loss or sports enhancement & 52 & & \\
\hline \multicolumn{4}{|l|}{ Center } \\
\hline Boston (ref.) & 26 & 1.00 Reference & 1.00 Reference \\
\hline Philadelphia & 13 & $2.00[1.02,3.91]$ & $1.85[0.83,4.11]$ \\
\hline Toronto & 8 & $1.56[0.70,3.47]$ & $1.71[0.73,4.02]$ \\
\hline San Diego & 5 & $1.25[0.48,3.26]$ & $1.40[0.48,4.13]$ \\
\hline New York & 0 & $0.00[0.00,]$. & $0.00[0.00,]$. \\
\hline \multicolumn{4}{|l|}{ Coffee Use } \\
\hline Never (ref.) & 10 & 1.00 Reference & 1.00 Reference \\
\hline Ever & 42 & $2.63[1.31,5.25]$ & $2.16[0.97,4.82]$ \\
\hline \multicolumn{4}{|l|}{ BMI } \\
\hline Underweight & 0 & $0.00[0.00,]$. & $0.00[0.00,]$. \\
\hline Normal (ref.) & 28 & 1.00 Reference & 1.00 Reference \\
\hline Overweight & 13 & $1.47[0.76,2.85]$ & $1.16[0.56,2.41]$ \\
\hline Obese & 11 & $2.18[1.08,4.40]$ & $1.83[0.83,4.04]$ \\
\hline Bladder or "female" problems & 56 & & \\
\hline \multicolumn{4}{|l|}{ Center } \\
\hline Boston (ref.) & 22 & 1.00 Reference & 1.00 Reference \\
\hline Philadelphia & 8 & $1.45[0.64,3.28]$ & $1.17[0.46,3.00]$ \\
\hline Toronto & 14 & $3.23[1.64,6.35]$ & $2.87[1.40,5.91]$ \\
\hline San Diego & 10 & $2.94[1.38,6.26]$ & $2.25[0.93,5.47]$ \\
\hline New York/Michigan & 2 & $4.14[0.95,17.99]$ & $1.26[0.14,11.63]$ \\
\hline \multicolumn{4}{|l|}{ Urinary Tract Infection } \\
\hline No & 42 & 1.00 Reference & 1.00 Reference \\
\hline Yes & 14 & $2.54[1.38,4.69]$ & $3.53[1.83,6.79]$ \\
\hline Probiotics & 92 & & \\
\hline \multicolumn{4}{|l|}{ Center } \\
\hline Boston (ref.) & 38 & 1.00 Reference & 1.00 Reference \\
\hline Philadelphia & 17 & $1.79[1.00,3.18]$ & $1.44[0.72,2.87]$ \\
\hline Toronto & 22 & $2.94[1.73,5.01]$ & $2.88[1.58,5.27]$ \\
\hline San Diego & 13 & $2.22[1.17,4.19]$ & $3.22[1.50,6.92]$ \\
\hline New York & 2 & $2.40[0.57,10.16]$ & $1.38[0.16,12.02]$ \\
\hline \multicolumn{4}{|l|}{ Alcohol Use } \\
\hline During Pregnancy & 27 & $0.81[0.51,1.30]$ & $0.62[0.36,1.09]$ \\
\hline Never (ref.) & 51 & 1.00 Reference & 1.00 Reference \\
\hline Before Pregnancy & 14 & $0.56[0.31,1.02]$ & $0.45[0.23,0.90]$ \\
\hline \multicolumn{4}{|l|}{ Tea Use } \\
\hline Never & 17 & 1.00 Reference & 1.00 Reference \\
\hline Ever & 73 & $3.19[1.87,5.42]$ & $3.14[1.69,5.84]$ \\
\hline Lipids and omega fatty acids & 43 & & \\
\hline
\end{tabular}




\begin{tabular}{lccc}
\hline & No. Exposed & Crude OR $(\mathbf{9 5} \%$ CI $)$ & Adj OR $(\mathbf{9 5 \%}$ CI) \\
\hline Center & & & \\
Boston (ref.) & 18 & 1.00 Reference & 1.00 Reference \\
Philadelphia & 5 & $1.11[0.41,3.00]$ & $1.00[0.32,3.12]$ \\
Toronto & 11 & $3.10[1.46,6.61]$ & $2.87[1.26,6.54]$ \\
San Diego & 7 & $2.52[1.05,6.06]$ & $2.38[0.81,6.97]$ \\
New York & 2 & $5.06[1.15,22.28]$ & $2.04[0.21,19.94]$ \\
Tea Use & & & \\
Never & 8 & 1.00 Reference & 1.00 Reference \\
Ever & 35 & $3.25[1.50,7.02]$ & $2.76[1.18,6.46]$ \\
\hline
\end{tabular}

